\title{
Postpneumonectomy respiratory failure and acute respiratory distress syndrome: risk factors and outcome
}

\author{
Antonio Mazzella ${ }^{1}$, Giorgio Lo Iacono ${ }^{1}$, Marco Alifano ${ }^{2}$ \\ ${ }^{1}$ Division of thoracic surgery, European Institute of Oncology, Milan, Italy; ${ }^{2}$ Thoracic Surgery Department, Paris Center University Hospital, \\ Assistance Publique - Hôpitaux de Paris, Paris Descartes University, Paris, France \\ Contributions: (I) Conception and design: A Mazzella, M Alifano; (II) Administrative support: M Alifano; (III) Provision of study materials or patients: \\ A Mazzella; (IV) Collection and assembly of data: A Mazzella, G Lo Iacono; (V) Data analysis and interpretation: All authors; (VI) Manuscript \\ writing: All authors; (VII) Final approval of manuscript: All authors. \\ Correspondence to: Dr. Antonio Mazzella. Division of Thoracic Surgery, European Institute of Oncology, Via Ripamonti, 435 - 20141 Milan, Italy. \\ Email: antonio.mazzella@ieo.it.
}

\begin{abstract}
Pneumonectomy is related with a high postoperative morbidity and mortality rate, ranging from $5 \%$ to $9 \%$. Post-pneumonectomy respiratory failure (ARF) acute lung injury (ALI) and acute respiratory distress syndrome (ARDS) are grave and disastrous complications in these patients, necessitating invasive mechanical ventilation (IMV). In different series reported in literature, ARDS after lung resection occurred in $1-8 \%$ of patients and the mortality amounts in a range between $30 \%$ to $80 \%$. We have reviewed the literature in order to clarify the different risk factors in the development of ARDS post pneumonectomy. According to different papers, the most important pre-operative risk factors are represented by age and sex, comorbidities (smoking, diabetes, COPD), pre-operative respiratory function and right side of pneumonectomy. Concerning peri and immediately post-operative management of these patients, the key role is represented by the IMV and the fluid infusion and cardiac preload during and after surgery. In summary, ALI and ARDS after pneumonectomy are closely linked to any direct or indirect pulmonary insult, responsible of endo-alveolar oedema. An inappropriate fluid infusion during or after surgery, may be exacerbate endo-alveolar oedema and encourage the development of ALI and ARDS. In this perspective, the best management of these patients should be achieved by a multidisciplinary team made by thoracic surgeons, respiratory physicians, anaesthesiologists, physiotherapists and nurses dedicated in ICUs.
\end{abstract}

Keywords: Pneumonectomy; acute respiratory distress syndrome (ARDS); respiratory failure

Received: 28 February 2020; Accepted: 23 March 2020; Published: 10 January 2021.

doi: $10.21037 /$ shc.2020.04.02

View this article at: http://dx.doi.org/10.21037/shc.2020.04.02

\section{Introduction}

In the era of parenchymal-sparing procedures (bronchial and bronchovascular sleeves), minimally invasive techniques or radiotherapic treatments for advanced lung cancers, the rate of pneumonectomy was reduced; nevertheless, in some cases pneumonectomy rests the only therapeutic approach to keep oncological radicality. However, it is associated with the highest postoperative morbidity $(1,2)$ and mortality rate, ranging from $5 \%$ to $9 \%(3,4)$ among pulmonary resections.

Post-pneumonectomy respiratory failure (ARF) and acute lung injury (ALI) represent an extremely serious and devastating complication, necessitating invasive mechanical ventilation (IMV); among these, patients developing acute respiratory distress syndrome (ARDS) post-pneumonectomy have an increased mortality rate (20-50\%) (5-7).

The first definition of ALI was given by American European Consensus Conference, to indicate a "syndrome of inflammation and increased permeability with pulmonary oedema" and several clinical - radiological alterations, not correlated to left atrial or pulmonary capillary hypertension. Berlin definition of ARDS in 2012 (8), modified by Kigali 
Table 1 Risk factors for the development of ARDS after pneumonectomy

\begin{tabular}{lcccccccc}
\hline Paper & Type of report/year & Age $(>60)$ & Sex (M) & Smoking & $\begin{array}{c}\text { Cardiac or respiratory } \\
\text { comorbidity }\end{array}$ & $\begin{array}{c}\text { CCl } \\
\text { Right-side }\end{array}$ & $\begin{array}{c}\text { Respiratory } \\
\text { function }\end{array}$ \\
\hline Kutlu et al. (10) & Original paper/2000 & $<0.01$ & $<0.01$ & $\mathrm{NI}$ & $\mathrm{NI}$ & $\mathrm{NI}$ & $\mathrm{NI}$ \\
Ruffini et al. (11) & Original paper/2001 & $\mathrm{NI}$ & $\mathrm{NI}$ & $\mathrm{NI}$ & $\mathrm{NI}$ & $\mathrm{NI}$ & $\mathrm{NS}$ \\
Alam et al. (12) & Original paper/2007 & $\mathrm{NI}$ & $\mathrm{NS}$ & 0.08 & $\mathrm{NI}$ & $\mathrm{NI}$ & $\mathrm{NS}$ \\
Jeon et al. (13) & Original paper/2009 & 0.08 & $\mathrm{NS}$ & $\mathrm{NS}$ & 0.08 & $\mathrm{NI}$ & $\mathrm{NS}$ & $\mathrm{NS}$ \\
Kim et al. (14) & Original paper/2010 & 0.001 & 0.05 & 0.01 & $\mathrm{NS}$ & $\mathrm{NI}$ & $\mathrm{NS}$ \\
Licker et al. (15) & Original paper/2003 & 0.023 & $\mathrm{NI}$ & $<0.001$ & $\mathrm{NS}$ & $\mathrm{NI}$ & 0.003 \\
Blanc et al. (16) & Original paper/2019 & 0.003 & $\mathrm{NS}$ & $\mathrm{NS}$ & 0.65 & 0.007 & 0.0001 & $\mathrm{NS}$ \\
\hline
\end{tabular}

We reported the value of multivariate analysis. If not available, the $\mathrm{P}$ value is referred to univariate analysis. NS, not significant; NI, not investigated; $\mathrm{CCl}$, Charlson Comorbidity index; ARDS, acute respiratory distress syndrome.

in 2016 (9), consisted in a respiratory failure during 1 week, linked to a known insult or new/worsening respiratory symptoms, associated to unilateral opacities on chest radiograph or CT, not related to cardiac disfunction or volume overload (echocardiography is mandatory to exclude hydrostatic oedema if no risk factor is present). According with these last data, ARDS was defined by the absence of hydrostatic or cardiogenic pulmonary oedema and partial pressure of arterial oxygen and fraction of inspired oxygen $\left(\mathrm{PaO}_{2} / \mathrm{FiO}_{2}\right) 300 \mathrm{mmHg}$ or less, with 3 categories of severity: mild (200 mmHg $<\mathrm{PaO}_{2} / \mathrm{FiO}_{2}<300 \mathrm{mmHg}$ ), moderate $\left(100 \mathrm{mmHg}<\mathrm{PaO}_{2} / \mathrm{FiO}_{2}<200 \mathrm{mmHg}\right)$ and severe $\left(\mathrm{PaO}_{2} / \mathrm{FiO}_{2}<100 \mathrm{mmHg}\right)$.

In different series reported in literature, ARDS after lung resection occurred in $1 \%$ to $8 \%$ of patients; mortality rate ARDS-related range from $30 \%$ to $80 \%$. This last aspect explains the importance of this life-treating condition and the role of prevention and of an immediate treatment (4-6,10-16).

The cause of lung injury in these patients is not really clear; the association between pneumonectomy and ARDS and study of risk factors are still argument of debate. At present, few studies have attempted to define the pre, peri- and post-operative risk factors for developing ALI and ARDS after pneumonectomy. Furthermore, some of these studies were conducted in the last decades, with a small cohorts of patients, and they don't investigate about all prognostic data. We have reviewed literature in order to clarify the most important and significative risk factors in the developing of ARDS after pneumonectomy for a correct pre-, peri- and post-operative management.

\section{Risk factors}

Development of ALI and ARDS after pneumonectomy is closely linked to any direct or indirect pulmonary insult. Generally, the response of pulmonary endothelium to these insults, the augmentation of endothelium permeability, the growth of reactive oxygen species (ROS) and generally the increase of inflammation is probably responsible of postoperative pulmonary oedema, representing the first step of ALI and ARDS (Table 1).

\section{Age/sex}

Several authors agree that age $>60 / 65$ years and male sex represent a factor risk to develop ARDS post pneumonectomy $(10,14-16)$.

\section{Comorbidities (diabetes, COPD and cardiac, smoking)}

Association between comorbidities (COPD, smoking, diabetes, alcohol assumption $>60 \mathrm{~g}$ of ethanol per day) and postoperative complication is known. COPD, diabetes and smoking are related with an increased rate of postoperative infections, pneumonia, bleeding with subsequent peri- and post-operative transfusion, cardiopulmonary insufficiency. All of these conditions are considered as risk factors for ARDS $(2,15,16)$. Particularly, smoking and alcohol assumption probably leads to a depletion of glutathione surfactant production and to an alteration in epithelial cell permeability with an increased vulnerability to infectious complications $(15,17)$. 


\section{Charlson comorbidity index (CCI)}

The CCI, descripted for the first time in 1987 (18), includes numerous clinical conditions and assess their relevance in the prediction of 1-year mortality. The score analyses 17 comorbidities and a weighted score is assigned to each of them. The cumulative sum of every score is an indicator of disease and a strong estimator of mortality. Blanc and colleagues report the association with a higher CCI (6 vs. 7, $\mathrm{P}>0.001$ ) and postpneumonectomy ARDS (16).

\section{Right-side pneumonectomy}

Right-side is an important risk factors for complication after pneumonectomy, especially for broncho-pleural fistula and early ARDS (16,19). Right lung is normally predominant in terms of perfusion and ventilation and postoperative pulmonary arterial pressure is higher after right than left pneumonectomy. Different reports $(20,21)$ demonstrated that pulmonary arterial pressure had higher values after right as opposed to left pneumonectomy. Particularly, right pneumonectomy causes a secondary pulmonary hypertension lied to a decrease of the pulmonary capillary bed and consequently a higher pulmonary vascular resistence, responsible of ALI or ARDS. In light of this, preoperative evaluation made by echocardiography and lung perfusion scan is mandatory. These non-invasive tests, even if not sensitive enough, could help to evaluate a correct pre-operative assessment; Fee and colleagues (21) suggest a right heart catheterization at rest and during exercise to predict postoperative ARDS.

\section{Pre-operative functional assessment (FEV1, DLCO, perfusion of resected lung)}

According to various reports, post-operative FEV1\% or DLCO ppo represent an important risk factors for complication after lung surgery, especially for ARDS post pneumonectomy $(11,12,14,16)$.

Alam et al. (12) demonstrate that there was an augmentation of lung damage associated to a reduction in postoperative lung function. Other authors $(11,14-16)$ showed a significant association between FEV1-ppo and postoperative ARDS.

Kim et al. (14) reported another interesting point about respiratory functionality: the percentage for perfusion fraction of resected lung; perfusion fraction level superior to $35 \%$ was related with higher occurrence of ARDS and early mortality than perfusion inferior to $35 \%$. If the perfusion in resected lung is already low, rebound effect linked to reduction of vascular bed and following postoperative pulmonary hypertension in the other lung will be reduced.

\section{IMV}

The role of IMV on development of ARDS has been discussed in different papers $(11,14,16)$. The pathogenetic mechanism of barotrauma in invasive ventilation is linked to stretch-activated cation channels, upregulation of inflammatory cytokines, augmentation of oxygen-derived free radicals and activated neutrophils. These events favourite micro-vascular alveolar permeability.

The protective role of low Tidal volume, low plateau pressure and positive end-expiratory pressure (PEEP) for ARDS have been demonstrated and confirmed by clinical studies in animal models $(15,22)$.

Ruffini et al. (11) suggest the "lung protective strategies" consisting of a reduced tidal volume $(<10 \mathrm{~mL} / \mathrm{kg})$, pressurecontrolled ventilation and PEEP, for limit peak alveolar pressures and assuring maximum alveolar recruitment. The authors recommend periodic volume recruitment manoeuvres with temporary increases of PEEP and a constant tidal volume, maintained for two ventilatory cycles every 30 minutes. This particular ventilation way could assure an elevating distending pressure only for a limited time.

Other studies $(16,23)$ have also suggested that a Tidal volume of $6 \mathrm{~mL} / \mathrm{kg}$ of Tidal volume and plateau pressure $>25 \mathrm{cmH}_{2} \mathrm{O}$ could raise the danger of postoperative lung damage. Licker et al. (15) used a barotrauma index, focusing on duration of ventilation, increased inspiratory pressure $\left(>10 \mathrm{cmH}_{2} \mathrm{O}\right)$ that represents the strongest risk factor for ALI and ARDS. Generally, fraction of inspired oxygen $\left(\mathrm{FiO}_{2}\right)$ should range between $30-100 \%$ in order to reach a $\mathrm{PaCO}_{2}$-level of 30-45 $\mathrm{mmHg}$ and oxygen saturation $>92 \%$, in order to avoid bigger peak inspiratory pressure (PIP) $\left(>50 \mathrm{cmH}_{2} \mathrm{O}\right)$ and gas trapping at end expiration.

However, these values and cut-off are still argument of debate. Generally speaking, all the reports agree on the protective role of low tidal volume and plateau pressure, applying PEEP during intraoperative IMV.

\section{Fluid infusion during anaesthesia and cardiac preload}

The effect of perioperative fluid administration has been poorly investigated in major lung resection but is an important contributory factor in the development of 
postoperative lung injury. An association between ALI and excessive fluid intake have been demonstrated in several reports $(10,12,15,24)$.

Licker and colleagues (15) suggest that the administration of large quantities of fluids $(<4 \mathrm{~L})$ in the first 24 hours, can favourite the ALI/ARDS in the following 72 hours after surgery. Another report identifies in patients who developed lung injury, a significantly higher median of received perioperative fluids than those in the control group (2,775 vs. 2,500 Ml, $\mathrm{P}=0.05)$. The same report demonstrates an odds ratio of 1.2 per increase of $500 \mathrm{~mL}$ of perioperative fluid administration.

After pneumonectomy occurs an increase in pulmonary vascular resistance and a reduction of lymphatic drainage (10,25); in addition, after lung amputation, the average blood flow increases from two to six times and the remaining lung is subjected to an excessive intravascular volume. In addition, surgical stress response can hurt capillary endothelium and augment protein-rich fluid into interstitium and alveolar space $(15,23,26)$; this condition, associated with previous comorbidity (BPCO, radiotherapy, surgical dissection) can further aggravate postoperative lung oedema. In the view of this, perioperative fluid overload may deteriorate this condition, favouriting ALI and ARDS.

\section{Pulmonary artery diameter}

In a recent report, Peretti and colleagues (27) reported the relationship between normalized pulmonary artery diameter (for body surface area) and respiratory failure and ARDS post-pneumonectomy. Multivariate analyses show that higher nPAD is independently associated with need of IMV, and occurrence of ARDS. However, echocardiographic estimates of pulmonary pressures don't show an association with the ARDS

\section{Conclusions}

ALI and ARDS are closely linked to any direct or indirect pulmonary insult, responsible of endo-alveolar oedema. An inappropriate fluid infusion during or after surgery, may be exacerbate endo-alveolar oedema and encourage the development of ALI and ARDS.

There are few reports in literature concerning ARDS post pneumonectomy. It is clear that IMV, peri and postoperative fluid infusion and comorbidities represent the crucial aspects to evaluate for the correct prevention and management of this complication. For this reason, the best management of these patients should be managed by a multidisciplinary team made by thoracic surgeons, respiratory physicians, anaesthesiologists, physiotherapists and nurses dedicated in ICUs.

\section{Acknowledgments}

Funding: None.

\section{Footnote}

Provenance and Peer Review: This article was commissioned by the Guest Editors (Lorenzo Spaggiari \& Luca Bertolaccini) for the series "The Role of Pneumonectomy in Thoracic Surgery in The Third Millennium", published in Shanghai Chest. This article has undergone external peer review.

Conflicts of Interest: All authors have completed the ICMJE uniform disclosure form (available at http://dx.doi. org/10.21037/shc.2020.04.02). The series "The Role of Pneumonectomy in Thoracic Surgery in The Third Millennium" was commissioned by the editorial office without any funding or sponsorship. The authors have no other conflicts of interest to declare.

Ethical Statement: The authors are accountable for all aspects of the work in ensuring that questions related to the accuracy or integrity of any part of the work are appropriately investigated and resolved.

Open Access Statement: This is an Open Access article distributed in accordance with the Creative Commons Attribution-NonCommercial-NoDerivs 4.0 International License (CC BY-NC-ND 4.0), which permits the noncommercial replication and distribution of the article with the strict proviso that no changes or edits are made and the original work is properly cited (including links to both the formal publication through the relevant DOI and the license). See: https://creativecommons.org/licenses/by-nc-nd/4.0/.

\section{References}

1. Schussler O, Alifano M, Dermine H et al. Postoperative pneumonia after major lung resection. Am J Respir Crit Care Med 2006;173:1161-9.

2. Algar FJ, Alvarez A, Salvatierra A et al. Predicting pulmonary complications after pneumonectomy for lung cancer. Eur J Cardiothorac Surg 2003;23:201-8. 
3. Groth SS, Burt BM, Sugarbaker DJ. Management of Complications After pneumonectomy. Thorac Surg Clin 2015;25:335-48.

4. Janet-Vendroux A, Loi M, Bobbio A, et al. Which is the role of pneumonectomy in the era of parenchymalsparing procedures? Early/long-term survival and functional results of a single-center experience. Lung 2015;193:965-73.

5. Dulu A, Pastores SM, Park B, et al. Prevalence and mortality of acute lung injury and ARDS after lung resection. Chest 2006;130:73-8.

6. Tang SSK, Redmond K, Griffiths M, et al. The mortality from acute respiratory distress syndrome after pulmonary resection is reducing: a 10-year single Institutional experience. Eur J Cardiothorac Surg 2008;34:898-902.

7. Hamaji M, Keegan MT, Cassivi SD, et al. Outcomes in patients requiring mechanical ventilation following pneumonectomy. Eur J Cardiothorac Surg 2014;46:e14-9.

8. Ranieri VM, Rubenfeld GD, Thompson BT, et al. Acute Respiratory distress syndrome: the Berlin Definition. JAMA 2012;307:2526-33.

9. Riviello ED, Kiviri W, Twagirumugabe T, et al. Hospital Incidence and Outcomes of the Acute Respiratory Distress Syndrome Using the Kigali Modification of the Berlin Definition. Am J Respir Crit Care Med 2016;193:52-9.

10. Kutlu CA, Williams EA, Evans TW, et al. Acute lung injury and acute respiratory distress syndrome after pulmonary resection. Ann Thorac Surg 2000;69:376-80.

11. Ruffini E, Parola A, Papalia E, et al. Frequency and mortality of acute lung injury and acute respiratory distress syndrome after pulmonary resection for bronchogenic carcinoma. Eur J Cardiothorac Surg 2001;20:30-6.

12. Alam N, Park BJ, Wilton A, et al. Incidence and risk factors for lung injury after lung cancer resection. Ann Thorac Surg 2007;84:1085-91.

13. Jeon K, Yoon JW, Suh GY, et al. Risk factors for postpneumonectomy acute lung injury/acute respiratory distress syndrome in primary lung cancer patients. Anaesth Intensive Care 2009;37:14-9.

14. Kim JB, Lee SW, Park SI, et al. Risk factor analysis for postoperative acute respiratory distress syndrome and early mortality after pneumonectomy: the predictive value of preoperative lung perfusion distribution. J Thorac Cardiovasc Surg 2010;140:26-31.

15. Licker M, de Perrot M, Spiliopoulos A, et al. Risk factors for acute lung injury after thoracic surgery for lung cancer. Anesth Analg 2003;97:1558-65.

16. Blanc K, Zaimi R, Dechartres A et al. Early acute respiratory distress syndrome after pneumonectomy: Presentation, management, and short- and long-term outcomes. J Thorac Cardiovasc Surg 2018;156:1706-14.e5.

17. Tønnesen H, Petersen KR, Højgaard L, et al. Postoperative morbidity among alcohol abusers. Ugeskr Laeger 1994;156:287-90.

18. Charlson ME, Pompei P, Ales KL, et al. New method of classifying prognostic comorbidity in longitudinal studies: development and validation. J Chronic Dis 1987;40:373-83.

19. Mazzella A, Pardolesi A, Maisonneuve P, et al. Bronchopleural Fistula After Pneumonectomy: Risk Factors and Management, Focusing on Open-Window Thoracostomy. Semin Thorac Cardiovasc Surg 2018;30:104-13.

20. Foroulis CN, Kotoulas CS, Kakouros S, et al. Study on the late effect of pneumonectomy on right heart pressures using Doppler echocardiography. Eur J Cardiothorac Surg 2004;26:508-14.

21. Fee HJ, Holmes EC, Gewirtz HS, et al. Role of pulmonary vascular resistance measurements in preoperative evaluation of candidates for pulmonary resection. J Thorac Cardiovasc Surg 1978;75:519-24.

22. Licker M, Diaper J, Villiger Y, et al. Impact of intraoperative lung-protective interventions in patients undergoing lung cancer surgery. Crit Care 2009;13:R41.

23. Evans RG, Naidu B. Does a conservative fluid management strategy in the perioperative management of lung resection patients reduce the risk of acute lung injury? Interact Cardiovasc Thorac Surg 2012;15:498-504.

24. Chau EH, Slinger P. Perioperative fluid management for pulmonary resection surgery and esophagectomy. Semin Cardiothorac Vasc Anesth 2014;18:36-44.

25. Little AG, Langmuir VK, Singer AH, et al. Hemodynamic pulmonary edema in dog lungs after contralateral pneumonectomy and mediastinal lymphatic interruption. Lung 1984;162:139-45.

26. Zeldin RA, Normandin D, Landtwing D, et al. Postpneumonectomy pulmonary edema. J Thorac Cardiovasc Surg 1984;87:359-65.

27. Peretti M, Hervochon R, Loi M, et al. Predictors of postpneumonectomy respiratory failure and ARDS: usefulness of normalized pulmonary artery diameter. Intensive Care Med 2018;44:1357-9.

doi: $10.21037 /$ shc.2020.04.02

Cite this article as: Mazzella A, Lo Iacono G, Alifano M. Postpneumonectomy respiratory failure and acute respiratory distress syndrome: risk factors and outcome. Shanghai Chest 2021;5:8. 